\title{
Landscape-Based Assessment of Human Disturbance for Michigan Lakes
}

\author{
Lizhu Wang • Kevin Wehrly • James E. Breck • \\ Lidia Szabo Kraft
}

Received: 12 February 2010/Accepted: 23 June 2010/Published online: 13 July 2010

(C) Springer Science+Business Media, LLC 2010

\begin{abstract}
Assessment of lake impairment status and identification of threats' type and source is essential for protection of intact, enhancement of modified, and restoration of impaired lakes. For regions in which large numbers of lakes occur, such assessment has usually been done for only small fractions of lakes due to resource and time limitation. This study describes a process for assessing lake impairment status and identifying which human disturbances have the greatest impact on each lake for all lakes that are 2 ha or larger in the state of Michigan using readily available, georeferenced natural and human disturbance databases. In-lake indicators of impairment are available for only a small subset of lakes in Michigan. Using statistical relationships between the in-lake indicators and landscape natural and human-induced measures from the subset lakes, we assessed the likely human impairment condition of lakes for which in-lake indicator data were unavailable using landscape natural and human disturbance measures. Approximately $92 \%$ of lakes in Michigan were identified as being least to marginally impacted and about $8 \%$ were moderately to heavily impacted by landscape human disturbances. Among lakes that were heavily impacted, more inline lakes (92\%) were impacted by human disturbances than disconnected $(6 \%)$ or headwater lakes $(2 \%)$. More small lakes were impacted than medium to large lakes. For inline lakes, $90 \%$ of the heavily impacted lakes were less than 40 ha, $10 \%$ were between 40 and 405 ha, and 1\% was greater than 405 ha. For
\end{abstract}

L. Wang $(\varangle) \cdot$ K. Wehrly · J. E. Breck · L. S. Kraft Institute for Fisheries Research, Michigan Department of Natural Resources and Environment and University of Michigan, 212 Museum Annex, 1109 N. University, Ann Arbor, MI 48109, USA

e-mail: lizuwang@umich.edu disconnected and headwater lakes, all of the heavily impacted lakes were less than 40 ha. Among the anthropogenic disturbances that contributed the most to lake disturbance index scores, nutrient yields and farm animal density affected the highest number of lakes, agricultural land use affected a moderate number of lakes, and pointsource pollution and road measures affected least number of lakes. Our process for assessing lake condition represents a significant advantage over other routinely used methods. It permits the evaluation of lake condition across large regions and yields an overall disturbance index that is a physicochemical and biological indicator weighted sum of multiple disturbance factors. The robustness of our approach can be improved with increased availability of high-resolution disturbance datasets.

Keywords Bioassessment - Nutrient - Lake condition · Catchment $\cdot$ Disturbance index

\section{Introduction}

Natural and man-made lakes in the United States and many other parts of the world are substantially impacted by human activities that occur within the lakes, along lake shorelines, and in lake catchments, as well as by humanreleased materials in the atmosphere. For large geographic areas, such as a state or a multistate region, usually insufficient field data collected from individual lakes are available for identifying how many and which lakes are affected, the geographic distribution of those lakes, and the seriousness in impairment of those lakes. Such information is essential for developing effective lake management strategies to maintain and improve water quality, aquatic habitats, fisheries, and other recreational uses. Such information 
is also necessary to inform policy makers and to meet the requirements of the US Clean Water Act. Section 305b requires states and tribes to prepare a comprehensive inventory of the condition of their waters and Section 303d requires states and tribes to list all waters not attaining their designated uses (http://www.epa.gov/owow/monitoring/ 305bguide/v1ch1.pdf).

Many state and federal agencies have established comprehensive monitoring and assessment programs to meet these information needs. A common sampling design used by water resource agencies is to target lakes for which local and catchment human influences are high or where information is needed for assessing compliance or for making regulatory or management decisions. Targeted sampling provides information for specific lakes and can be used for determining whether the sampled lakes meet their designated uses. This sampling design, however, cannot provide information on the overall quality of lakes in a state or a region because targeted lakes are rarely representative of the larger population of lakes. To assess regional conditions, state and federal agencies typically employ a stratified random selection of lakes from a particular basin or ecoregion. In this design, a portion of lakes are sampled within each basin or ecoregion on a rotational basis with a target of completing an entire state or all ecoregions within 5-10 years. Stratified random sampling provides reasonable estimates of the proportion of lakes that are impaired for a particular basin or ecoregion. This design, however, does not provide information on unsampled lakes, and the status of many individual lakes in the basin or ecoregion remains unknown. Assessing the status of all lakes, including unsampled waters, would be extremely helpful in directing regulatory and management efforts. Consequently, an assessment approach that can be used for not only assessing what proportion of lakes is impacted by human activities but also for assessing impairment conditions of unsampled lakes is highly desirable.

Another challenge to assessing lake condition involves choosing appropriate stressors and indicators so that various physical, chemical, and biological conditions can be realistically assessed with a limited amount of resources and time. The US Environmental Protection Agency (US EPA) recommended numerous core and supplemental indicators to state and tribal water monitoring and assessment programs (USEPA 2003). The US EPA also recommended that agencies use a different set of indicators to monitor waters with different designated uses (USEPA 2003). Assessing the recommended suite of indicators, which includes conductivity, temperature, water clarity, dissolved oxygen (DO), $\mathrm{pH}$, nutrients, eutrophic condition, chlorophyll- $a$, Secchi depth, pathogens, trace metals, landscape conditions, sediment contaminants, catchment land uses, and at least two biological assemblages, makes the assessment program very expensive and time-consuming. Assessing the entire suite of indicators becomes cost-prohibitive when many lakes are to be sampled, and in states or regions where a large number of lakes occur, only a small proportion of lakes can be sampled. Hence, a screening tool is needed for identifying lakes that need intensive sampling and lakes that can be assessed using less intensive field sampling or alternative approaches (Wang and others 2008). Such a screening tool would provide a cost-effective means to obtain information on the condition of all lakes in a region.

It is even more challenging to integrate all stressors and indicators so that overall conditions within and among lakes can be assessed and compared. The most commonly used index for lake condition assessment is Carlson's Trophic State Index (TSI; Carlson 1977). Carlson's TSI is an index of potential lake productivity and uses chlorophyll concentration, Secchi depth, and total phosphorus to independently estimate algal biomass. Carlson's TSI has limited utility in assessing overall lake conditions because it only measures trophic state. In addition, the TSI does not distinguish whether high algal production results from natural or human-derived sources and can only be used in lakes that have few rooted aquatic plants and little nonalgal turbidity. More recently, considerable effort has been devoted to developing biological indexes because they are believed to better represent overall lake conditions. Efforts have been made to develop indexes of biotic integrity for lakes using fish (e.g., Drake and Pereira 2002; Lyons and others 2000; Minns and others 1994; Schulz and others 1999), macroinvertebrates (e.g., Lewis and others. 2001; Ma and others. 2008), macrophytes (Melzer 1999; Nichols and others 2000), and diatoms (e.g., Dixit and Smol 1994; StengerKovács and others 2007). The success of these biotic indexes in accurately depicting overall lake condition has been mixed when compared to alternative measures of lake condition (e.g., Drake and Valley 2005; Schulz and others 1999). Because each index assesses different aspects of lake impairment and reference conditions need to be identified for each lake type, the interpretation of assessment results from different indicators for comparisons among lakes is often challenging. Hence, an index that integrates all of the measured indicators and that reflects the overall physical, chemical, and biological conditions of lakes, without bias toward one or the other, is needed.

Identifying dominant individual disturbance factors that determine lake condition is essential for directing management efforts toward impairment remediation. Although biological indexes are believed to integrate the effects of all disturbance sources, types, and pathways for river systems (Fausch and others 1990; Karr and Chu 1999), connections between biological indexes and specific human disturbances are complex and poorly understood. This lack of understanding makes it difficult to pinpoint sources of 
ecosystem change and to prescribe preventive or restorative management actions (Norris and Hawkins 2000; Suter and others 2002; USEPA 2000). Therefore, it would be highly desirable to develop an assessment approach that could identify sources of degradation for each lake.

Most lake condition assessments have focused on in-lake physicochemical and biological conditions because of the unavailability of large-scale human-disturbance data and the resources required to delineate lake tributary and local catchment boundaries. As the availability of regional databases and the development of geographic information technologies have increased, using landscape disturbances to directly assess aquatic system condition has become feasible and cost-effective (Danz and others 2007; Mattson and Angermeier 2007; Wang and others 2006a, 2008). Landscape-based assessments are attractive because they rely on the naturally defined hydrologic catchment as the integrating management unit. Consequently, landscape-based assessments can be used to assess lake resources as well as the streams and rivers that flow into lakes and the lands that contribute water to the lakes. Thus, landscape-based assessments provide an integrated, holistic strategy for protecting and managing aquatic resources and achieving broader environmental protection objectives (USEPA 2003).

In this study, we adapted for lakes in Michigan an approach that was developed for streams (Wang and others 2008) for quantifying human-disturbance gradients and identifying key disturbance factors. This approach incorporates natural environmental variability of landscapes at multiple spatial scales and uses readily available anthropogenic disturbances and lake-specific physicochemical and biological measures to link levels of human disturbance with those physicochemical and biological changes to assess lake conditions. Our specific objectives were to (1) compare the relative importance of landscape disturbances at tributary and local catchment scales in influencing in-lake indicators, (2) assess human-disturbance gradients for all lakes that are 2 ha (5 acres) or larger in the state of Michigan based on observed relationships between landscape human disturbances and in-lake physicochemical and biological measures, and (3) determine major sources of degradation for lakes that are moderately to heavily impacted and identify potential threats for lakes that are least impacted.

\section{Methods}

Lake Polygons and Their Associated Catchment Boundaries

We first identified all natural and man-made lake polygons that are 2 ha or larger from the 1:24,000 National
Hydrography Dataset for the entire state of Michigan using a geographic information system (GIS; ESRI 2002). We then delineated tributary and local catchment boundaries for all lakes. We defined a tributary catchment as the land area where surface water drains directly into rivers and then into a lake. We defined a local catchment as the land area where surface runoff drains directly into a lake. Catchment boundaries were delineated using GIS algorithms to identify runoff directions based on 30-m resolution Digital Elevation Model (DEM) and to restrict the outmost catchment boundaries using a 12-digit Hydrological Unit (HU) or aggregated HUs that were developed by Michigan Department of Natural Resources and Environment (MDNRE).

We calculated several measures of lake landscape position and morphometry that are known to strongly influence lake physicochemical and biological characteristics (Martin and Soranno 2006). These measures included lake order calculated as the stream order of the largest tributary flowing into each lake, total number of lakes in the tributary catchment of each lake, total number of lakes downstream between each lake and the Great Lakes (all rivers in Michigan flow into the Great Lakes), tributary and local catchment areas, shoreline development index $\left[D=L /\left(2(\pi A)^{1 / 2}\right]\right.$, where $L$ is the perimeter and $A$ is lake area), and lake fetch (length of the longest unobstructed distance across a lake). We identified lakes based on hydrologic connectivity, including both perennial and intermittent streams. Inline lakes were defined as having both inflows and outflows in a river network; headwater lakes were defined as having only outflows; and disconnected lakes were defined as having no inflows or outflows.

\section{Natural and Human-Disturbance Landscape Variables}

We calculated natural and human disturbance measures in tributary and local catchments for lakes from databases of various sources. For natural landscape measures, nonhuman-disturbance land-cover types were measured from 2001 Michigan Land Use/Cover Data (http://www.mcgi. state.mi.us/mgdl). Surficial geology texture and formation types were calculated from the Michigan Quarternary geology geographic theme under geology (http://www. mcgi.state.mi.us/mgdl/?rel=ext\&action=sext). Soil permeability was calculated based on the US Geological Survey's soils data for the conterminous United States derived from the Natural Resource Conservation Service state soil geographic (STATSGO) database (http://water.usgs.gov/GIS/ dsdl/ussoils_04.e00.gz). Annual and July mean air temperatures were obtained from the Oregon State University/ Spatial Climate Analysis Service for the conterminous United States (www.climatesource.com/us/fact_sheets/ fact_tmean_us.html). Annual growing degree days and annual precipitation were also obtained from the Oregon 
State University/Spatial Climate Analysis Service for the conterminous United States (www.climatesource.com/us/ fact_sheets/fact_gdd50f_us.html; www.climatesource.com/ us/fact_sheets/fact_precip_us.html). Lake elevation and catchment slopes were calculated based on the DEM using GIS.

For human-disturbance measures (Table 1), urban and agricultural land uses were determined from 2001 Michigan Land Use/Cover Data (http://www.mcgi.state.mi.us/mgdl). Percent of catchment area in urban and agriculture and ratio of catchment area in urban and agriculture to lake area were computed for all tributary and local catchments. Length of roads and number of road crossings in the catchment per catchment area and per lake area were calculated using the Michigan Geographic Data Library roads (http://www. mcgi.state $\cdot \mathrm{mi} . u s / \mathrm{mgdl} /$ ?rel=ext\&action=sext, under Transportation). Numbers of residents in the catchment per catchment area and per lake area were calculated using 2000 census data (http://www.mcgi.state.mi.us/mgdl/?rel= ext\&action=sext, under the Census). Yields of total nitrogen and total phosphorus were calculated as kilograms per catchment area and per lake area per year from data that was predicted by the US Geological Survey (USGS) using the Spatially Referenced Regressions on Watershed Attributes model (Smith and others 1997; http://water.usgs.gov/ nawqa/sparrow/wrr97/results.html). The total number of permitted discharge facilities in each catchment and the number of permitted discharge facilities directly connected to streams in each catchment were obtained from the MDNRE unpublished database and were calculated as the number of facilities per catchment area and as the number of facilities per lake area. The total number of toxic release sites in the catchment and the number of toxic release sites directly connected with streams were obtained from the US EPA's toxic release inventory (http://www.epa.gov/ tri/tridata/index.htm) and were calculated as the number of facilities per catchment area and per lake area. The proportion of catchment area and the ratio of catchment area to lake area that were treated with fertilizers, herbicides, insecticides, and manure were calculated using the US Department of Agriculture (USDA)'s 2002 Census of Agriculture database (http://www.agcensus.usda.gov/) and the USDA's 2002-2005 Performance Results System (http://ias.sc.egov.usda.gov/prshome/default.html). Numbers of active mining sites per catchment area and per lake area were calculated from USGS's mineral resource database (http://tin.er.usgs.gov/mineplant/).

\section{In-Lake Variables}

Fish assemblage composition data were from the MDNRE Fish Collection System (MDNRE unpublished data). We selected lakes with fish data collected using gill nets, trap nets, beach seines, and electrofishing following the standard MDNRE status and trends protocol (Wehrly and others 2010). There were 287 lakes with fish data that met our data selection criteria. Using these fish data, we calculated the index of biotic integrity (IBI) following the method developed for Minnesota lakes (Drake and Pereira 2002). The IBI consisted of 16 metrics, including 2 metrics calculated from gill nets, 3 from trap nets, 3 from nearshore gear (seining and eletrofishing), and 8 species-richness metrics from a combination of all gear types. Because the Minnesota lake IBI was developed for lakes less than 202 ha, its ability to determine fish biotic condition is unknown for lakes larger than 202 ha in our dataset. Despite this uncertainty, we used this IBI because it is the only validated IBI version available for Midwestern lakes and because the majority of Michigan lakes used in our analysis are smaller than 202 ha.

Lake indicator and stressor data were obtained from various sources, including the USGS's Water Data for the Nation, data maintained by MDNRE, MDNRE Fish Collection Systems, and the Institute for Fisheries Research Water Atlas Database (Breck 2004). From these databases, we selected 750 lakes having total nitrogen, total phosphorus, chlorophyll- $a$, Secchi depth data, and DO profiles that were collected during the lake stratification period (July, August, and September). The amount of hypoxia and anoxia in each lake were estimated as the depth and proportion of the water column having oxygen concentrations below $4.0 \mathrm{mg} / \mathrm{L}$ and $0.5 \mathrm{mg} / \mathrm{L}$ during the stratification period, respectively.

In-lake physical habitat-disturbance data included percent of shoreline armoring (sea walls, riprap, and other man-made structures), number of houses per kilometer of shoreline, number of docks per kilometer of shoreline, and number of submerged trees that were $7.6 \mathrm{~cm}$ or larger in diameter per kilometer of shoreline. These measures were visually estimated using standard lake survey protocol (Wehrly and others 2010) from 2002 to 2009.

Lake mean depth and maximum depth were obtained by digitizing bathymetry maps. Lake ice-free days and mean and maximum ice-free surface water temperatures were modeled based on the relationship among mean annual air temperature, fetch, lake area, and measured surface water temperature for a subset of lakes (Breck unpublished data; Shuter and others 1983).

\section{Data Analyses}

We organized our data into two datasets. The first dataset included all lakes in Michigan that were 2 ha or larger and the second was a subset of these lakes that had in-lake variables. The subset-lake dataset consisted of 152 various size lakes distributed across the state (Fig. 1). The criteria 
Table 1 Mean, median, range, and standard deviation of human-disturbance factors for lakes that are greater or equal to 2 ha in Michigan, from which lake human disturbance was assessed

\begin{tabular}{|c|c|c|c|c|}
\hline Disturbance variables & Mean & Median & Range & $\begin{array}{l}\text { Standard } \\
\text { deviation }\end{array}$ \\
\hline \multicolumn{5}{|l|}{ Agricultural disturbance variables } \\
\hline Cattle density (No./ $/ \mathrm{km}^{2}$ catchment) & 4 & 0 & $0-56$ & 6 \\
\hline Cattle density (No./km² lake area) & 428 & 0 & $0-110,041$ & 2,888 \\
\hline Manure, pesticide, herbicide application ( $\%$ of catchment) & 17 & 1 & 0-204 & 31 \\
\hline Manure, pesticide, herbicide application $\left(\mathrm{km}^{2}\right.$ catchment $/ \mathrm{km}^{2}$ lake area) & 217 & 3 & $0-17,636$ & 808 \\
\hline Other agriculture ( $\%$ of catchment $)$ & 10 & 1 & $0-100$ & 15 \\
\hline Other agriculture $\left(\mathrm{km}^{2}\right.$ catchment $/ \mathrm{km}^{2}$ lake area) & 1043 & 4 & $0-125,024$ & 5,370 \\
\hline Rowcrop (\% of catchment) & 6 & 0 & $0-100$ & 13 \\
\hline Rowcrop $\left(\mathrm{km}^{2}\right.$ catchment $/ \mathrm{km}^{2}$ lake area) & 883 & 0 & $0-278,181$ & 6,871 \\
\hline Total nitrogen yield $\left(\mathrm{kg} / \mathrm{km}^{2} /\right.$ year $)$ & 652 & 428 & $0-2,900$ & 461 \\
\hline Total nitrogen yield $\left(1000 \mathrm{~kg} / \mathrm{km}^{2}\right.$ lake area/year $)$ & 65 & 6 & $0-16,106$ & 374 \\
\hline Total phosphorus yield $\left(\mathrm{kg} / \mathrm{km}^{2} /\right.$ year $)$ & 48 & 23 & 0-692 & 69 \\
\hline Total phosphorus yield $\left(1000 \mathrm{~kg} / \mathrm{km}^{2}\right.$ lake area/year) & 5 & 0 & $0-1,808$ & 37 \\
\hline \multicolumn{5}{|l|}{ Urban variables } \\
\hline Commercial-industrial ( $\%$ of catchment) & 1 & 0 & $0-100$ & 5 \\
\hline Commercial-industrial $\left(\mathrm{km}^{2}\right.$ catchment $/ \mathrm{km}^{2}$ lake area) & 58 & 0 & $0-18,397$ & 495 \\
\hline Human population (No./km² catchment) & 58 & 16 & $0-3,979$ & 157 \\
\hline Human population (No./km² lake area) & 5,322 & 167 & $0-1,637,443$ & 42,639 \\
\hline Imperviousness (\% of catchment) & 2 & 0 & $0-60$ & 6 \\
\hline Imperviousness $\left(\mathrm{km}^{2}\right.$ catchment $/ \mathrm{km}^{2}$ lake area) & 189 & 0 & $0-59,713$ & 1,597 \\
\hline Other urban (\% of catchment) & 0 & 0 & $0-51$ & 2 \\
\hline Other urban $\left(\mathrm{km}^{2}\right.$ catchment $/ \mathrm{km}^{2}$ lake area) & 26 & 0 & $0-15,169$ & 265 \\
\hline Resident (\% of catchment) & 1 & 0 & $0-60$ & 4 \\
\hline Resident $\left(\mathrm{km}^{2}\right.$ catchment $/ \mathrm{km}^{2}$ lake area $)$ & 118 & 4 & $0-47,403$ & 916 \\
\hline Road-park (\% of catchment) & 3 & 1 & $0-90$ & 5 \\
\hline Road-park $\left(\mathrm{km}^{2}\right.$ catchment $/ \mathrm{km}^{2}$ lake area) & 202 & 15 & $0-67,096$ & 1,229 \\
\hline Shoreline house density (No./km lake shoreline) & 10 & 10 & $0-51$ & 8 \\
\hline \multicolumn{5}{|l|}{ Point-source variables } \\
\hline Mines (No./km² catchment) & 0 & 0 & $0-48$ & 1 \\
\hline Mines (No./km² lake area) & 0 & 0 & $0-69$ & 1 \\
\hline US EPA's toxic release inventory sites do not drain to surface water (No. $/ \mathrm{km}^{2}$ catchment) & 0 & 0 & $0-327$ & 4 \\
\hline US EPA's toxic release inventory sites do not drain to surface (No. $/ \mathrm{km}^{2}$ lake area) & 1 & 0 & $0-192$ & 6 \\
\hline US EPA's toxic release inventory sites draining to surface (No./ $\mathrm{km}^{2}$ catchment) & 0 & 0 & $0-123$ & 1 \\
\hline US EPA's toxic release inventory sites draining to surface (number $/ \mathrm{km}^{2}$ lake area) & 0 & 0 & $0-43$ & 1 \\
\hline MDEQ's permitted point-source facilities do not drain to surface water (No. $/ \mathrm{km}^{2}$ catchment) & 1 & 0 & $0-1,111$ & 17 \\
\hline MDEQ's permitted point-source facilities do not drain to surface water (No./km² lake area) & 1 & 0 & $0-1,666$ & 23 \\
\hline MDEQ's permitted point-source facilities draining to surface (No./km² catchment) & 4 & 0 & $0-2,154$ & 42 \\
\hline MDEQ's permitted point-source facilities draining to surface (No./km² lake area) & 2 & 0 & $0-970$ & 24 \\
\hline \multicolumn{5}{|l|}{ Other disturbance variables } \\
\hline Catchment runoff $(\mathrm{cm} /$ year $)$ & 33 & 33 & $18-53$ & 8 \\
\hline Catchment runoff $\left(\mathrm{dm}^{3} / \mathrm{year} / \mathrm{km}^{2}\right.$ lake area $)$ & 20.8 & 2.4 & $0-19,373$ & 249.3 \\
\hline Chlorine-sulfur atmospheric deposition (1000 kg/ha) & 129 & 15 & $0-39,654$ & 731 \\
\hline Road density $\left(\mathrm{km} / \mathrm{km}^{2}\right.$ catchment $)$ & 14 & 0 & $0-11,256$ & 244 \\
\hline Road density $\left(\mathrm{km} / \mathrm{km}^{2}\right.$ lake area) & 147 & 5 & $0-42,940$ & 838 \\
\hline Road crossings (No. $/ \mathrm{km}^{2}$ catchment) & 0 & 0 & $0-132$ & 2 \\
\hline Road crossings (No./km² lake area) & 32 & 0 & $0-13,419$ & 246 \\
\hline
\end{tabular}




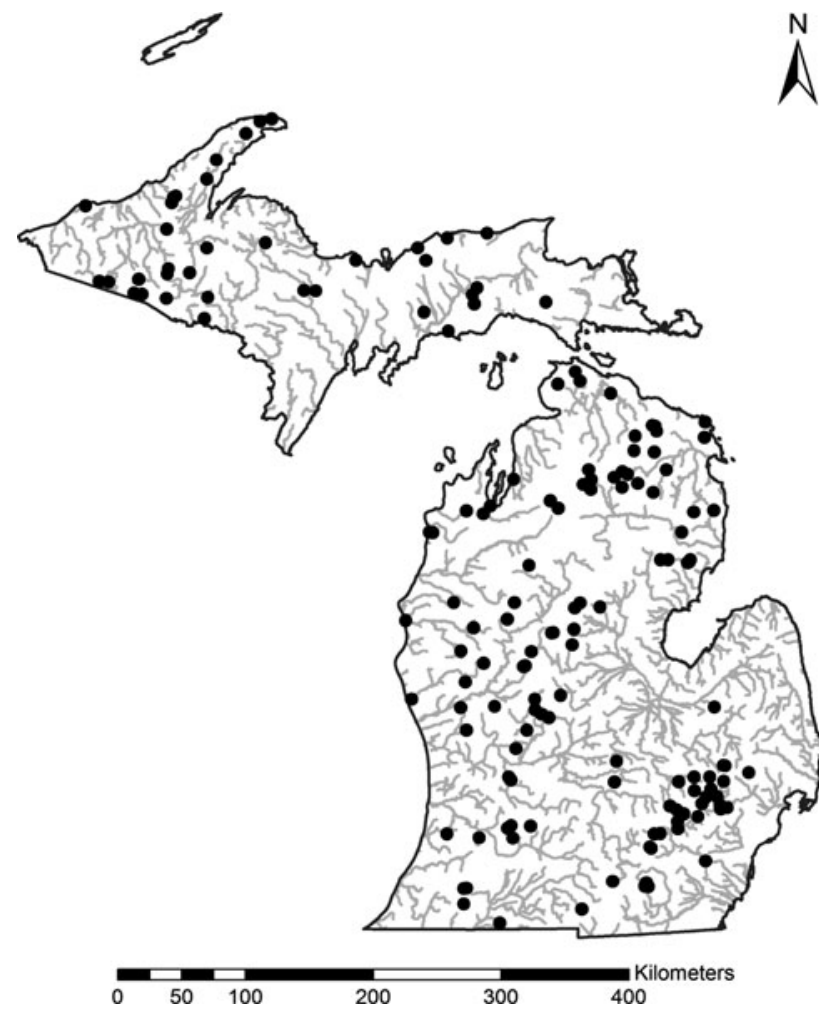

Fig. 1 Map of Michigan showing location of lakes where in-lake indicators and stressors were available for calculating weights for landscape disturbance variables

used to select the subset lakes were that they had to have all the lake morphology and indicator measures. Data from tributary and local catchments and descriptors of lake network position, climate, and physical setting were available for lakes in both datasets. We used the subsetlake dataset to develop models that describe relationships among in-lake lake condition indicators, natural variables, and human-disturbance measures. We then applied the models to the all-lake dataset to calculate lake-disturbance index scores and identify key disturbance factors that contributed most or posed the greatest potential threat to the lake condition for all lakes in Michigan.

To determine whether disturbances in tributary and local catchments should be weighted differently in calculating lake-disturbance index scores, we compared the relative importance of landscape-disturbance factors at local and tributary catchment scales in influencing in-lake condition indicators. We divided our variables in the subset-lake dataset into three types: natural, human disturbance in local catchments, and human disturbance in tributary catchments. In this analysis, only lakes having tributary catchments were included and the relative influence of natural landscape variables at local and tributary catchment scales were lumped together because we were interested in comparing the relative importance of disturbances at the two spatial scales only. We performed canonical correspondence analyses (CCA) forward selection procedure using CANOCO software (ter Braak and Smilauer 1998) to select the natural and human-disturbance variables that were significantly $(P<0.10)$ correlated with CCA axes for each of the three data pairs: in-lake indicators paired with natural variables, in-lake indicators paired with human disturbances in local catchments, and in-lake indicators paired with human disturbances in tributary catchments. We used $P<0.10$ as our criterion for variable retention because at $P<0.05$ very few variables were retained and the analysis was not very informative. We then took the variables selected in the variable selection step and conducted a CCA partition procedure (Borcard and others 1992). The CCA partition procedure was used to estimate the relative importance of natural variables, human disturbances in local catchments, and human disturbances in tributary catchments in explaining the variation of in-lake indicators.

To prepare data for calculating lake-disturbance index scores, we first combined local and tributary catchment disturbance data because our aforementioned analyses indicated that the influence of disturbances in local and tributary catchments was similar. We also standardized the values of each disturbance variable from 0 to 100 by dividing the difference between the variable value and minimum value by the difference between maximum and minimum values for that variable and then multiplied by 100. This rescaling was intended to minimize the influence of the differences in measurement scales among disturbance variables and the nonlinear relationships between indicators and disturbances. We then categorized the disturbance variables into agriculture (12 variables), urban (13 variables), point source (10 variables), and other disturbances (7 variables) (Table 1). We last conducted Spearman rank correlations (SAS 2004) to identify natural variables that were significantly correlated with indicators for the subset-lake dataset. The significance of correlations was adjusted using a Bonferroni correction to minimize the influence of a large sample size on the likelihood of obtaining a significant $P$-value. A natural variable was selected if it was correlated with at least one indicator variable $(P<0.05)$ and was not strongly correlated $(<35 \%)$ with another natural variable. If two or more natural variables were correlated with an indicator variable but highly correlated to each other, the natural variable that was most strongly correlated with the indicator was selected.

To calculate lake-disturbance index scores, we first conducted principle component analyses (PCA) for each of the six groups of variables: in-lake indicators, natural variables, and the four disturbance variable groups using SAS (2004). For each of the variable groups, we retained 
all PCA axes that explained more than $10 \%$ of the variance in that group's variables. We then computed, for each lake, a composite metric by multiplying each variable value by its PCA loading to calculate a weighted measure for each retained PCA axis in each of the six groups of initial variables.

$$
\begin{gathered}
I_{i p}=\sum_{j=1}^{n_{I}} Y_{i j} \cdot P I_{j p}, \quad D_{i p d}=\sum_{j=1}^{n_{d}} X_{i j d} \cdot P D_{j p d}, \\
N_{i p}=\sum_{j=1}^{n_{N}} Z_{i j} \cdot P N_{j p}
\end{gathered}
$$

where $I_{i p}$ is the composite indicator metric for lake $i$ along PCA axis $p, D_{i p d}$ is the composite disturbance metric for lake $i$ along PCA axis $p$ in disturbance group $d, N_{i p}$ is the composite natural metric for lake $i$ along PCA axis $p, Y_{i j}$ is the value for lake $i$ of indicator variable $j, X_{i j d}$ is the value for lake $i$ of disturbance variable $j$ in disturbance group $d, Z_{i j}$ is the value for lake $i$ of natural variable $j, P I_{j p}$ is the PCA loading for indicator variable $j$ along PCA axis $p, P D_{j p d}$ is the PCA loading for disturbance variable $j$ along PCA axis $p$ in disturbance group $d, P N_{j p}$ is the PCA loading for natural variable $j$ along PCA axis $p, n_{I}$ is the number of variables in the indicator group, $n_{d}$ is the number of variables in disturbance group $d$, and $n_{N}$ is the number of variables in the natural group.

We next conducted canonical correlation analyses (CCRA; SAS 2004) using the composite indicator metrics as dependent variables and the composite disturbance and natural metrics as independent variables to produce weighting factors for the independent variables. Weighting each axis of the independent variables was necessary because different disturbance and natural variables impacted indicators differently despite having similar PCA scores. Canonical correlation is a multivariate statistical technique used for analyzing relationships between a set of multiple dependent variables and a set of multiple independent variables. When a strong and significant relationship between indicator variables and disturbance factors was revealed, the linear combination of predictor variables represented an index of disturbance conditions. The set of weights associated with this linear combination could then be used as a set of coefficients for transforming the disturbance variables from each sample unit into an environmental disturbance index (Laessig and Duckett 1979). In our case, we also included the retained natural variable axes as predictor variables in the CCRA to account for the influences of major nondisturbance factors on the indicator variables. The inclusion of the natural variable axes in this process is critical because the indicators are not only influenced by disturbances but also by natural variables. Canonical correlation analyses is well suited for quantifying the effects of disturbance variables because this approach can account for the direct influence of natural variables as well as the interaction among natural and disturbance variables.

We last computed the final lake-disturbance index score using the CCRA weighting factors and the composite disturbance metrics:

$S_{i}=\sum_{d=1}^{4} \sum_{p=1}^{m_{d}} \beta_{p d} \cdot D_{i p d}$

where $S_{i}$ is the lake condition score for lake $i, \beta_{p d}$ is the CCRA weighting factor for axis $p$ in disturbance group $d$, and $m_{d}$ is the number of retained PCA axes for disturbance group $d$.

The disturbance index scores were rescaled to a range from 0 to 100 for ease of interpretation. Using the PCA process and the weighting factors generated by the CCRA process from the subset lakes, we calculated disturbance index scores for all lakes, including lakes that did not have in-lake indicator data but had disturbance data.

The condition of a specific lake was measured by the disturbance index score that was calculated using multiple disturbance factors. Hence, the key disturbance factors that contributed most to the disturbance index score could be identified for each lake. We identified the top two disturbance factors for each lake that contributed most to the lake disturbance index score. These two factors and their associated spatial scales for each lake could be used as management targets for improving the condition of each lake.

\section{Results}

There were 9260 lakes 2 ha or larger in Michigan based on the 1:24,000 National Hydrography Dataset. Among them, $39 \%$ were inline lakes, $15 \%$ were headwater lakes, and $46 \%$ were disconnected lakes. The average lake size for inline lakes (69 ha) was much larger than for headwater (18 ha) or disconnected lakes (11 ha). Lake surface area ranged from 2 to 8124 ha, with a median of 6 ha. About $88 \%$ of the lakes were between 2 and 40 ha, $11 \%$ were between 40 and 405 ha, and 1\% were greater than 405 ha.

Average agricultural land use (sum of rowcrop and other agriculture) in lake catchments was about $16 \%$ and urban land use (sum of commercial-industrial, resident, road-park, and other urban) was about 5\% (Table 1). Twenty-four lakes had more than $90 \%$ agricultural land and 30 lakes had greater than $80 \%$ urban land in their catchments. Lakes having high percentages of agricultural and urban land use were all disconnected lakes and generally had small catchment areas $\left(<3.0 \mathrm{~km}^{2}\right)$. The average human population density was $58 / \mathrm{km}^{2}$ (range: 0-3979); the imperviousness area was $2 \%$ (range: 0-60); the road density was $14 \mathrm{~km} / \mathrm{km}^{2}$ (range: $0-11,256)$; and the road crossing was $0.2 / \mathrm{km}^{2}$ (range: $0-132$ ) in the lake catchments. 
The average ratio in catchment area to lake area was 1925 for agricultural land (range: 0-338,122); 404 for urban land (range: 0-136,691); and 189 for imperviousness (range: 0-59,713). The average density based on lake area was 5322 people $/ \mathrm{km}^{2}$ (range: 0-1,637,442) for human population, $147 \mathrm{~km} / \mathrm{km}^{2}$ (range: 0-42,490) for roads, and 32 bridges or culverts $/ \mathrm{km}^{2}$ (range: $0-13,419$ ) for road crossings.

The 152 lakes used for developing relationships between in-lake indicators and human-disturbance measures encompassed the range in lake size, type, and conditions observed in the larger population of lakes in Michigan. About $21 \%$ of the lakes were between 2 and 40 ha, $70 \%$ were between 40 and 405 ha, and $9 \%$ were greater than 405 ha, indicating that more medium to large lakes were present in the subset of lakes compared with the entire lake population. About $64 \%$ of those lakes were inline, $12 \%$ were headwater, and $24 \%$ were disconnected, indicating that a greater proportion of inline lakes were present in the subset of lakes compared with the entire lake population. Among those lakes, 27 had more than $30 \%$ of the water column anoxic (DO $<0.5 \mathrm{mg} / \mathrm{L}) ; 17$ lakes had more than $50 \%$ of their shoreline armored with seawalls or other manmade shoreline structures; 19 lakes had total phosphorus greater than $15 \mu \mathrm{g} / \mathrm{L} ; 9$ lakes had chlorophyll- $a$ greater than $10 \mu \mathrm{g} / \mathrm{L}$; and 23 lakes had Secchi disk depth less than $2 \mathrm{~m}$ (Table 2).

Our CCA partition analyses indicated that human disturbances in tributary and local catchments explained similar amounts of variance for the in-lake indicator variables. Natural and human-disturbance variables at different spatial scales explained $82 \%$ of the variation for in-lake indicators. Of the total variance explained, about $16 \%$ was attributed to disturbances in tributary catchment, $15 \%$ was attributed to disturbances in local catchment, and 39\% was attributed to variables that describe natural variation in tributary catchments, local catchments, lake network, and lake morphology. About $30 \%$ of the variance for in-lake indicators was explained by the interactions among all the human-induced and natural variables at different spatial scales.

Of the 9260 inland lakes in Michigan that we assessed, about 3\% had human-disturbance scores greater than 75 (heavily impacted), 5\% were between 50 and 75 (moderately impacted), $29 \%$ were between 25 and 50 (marginally impacted), and 63\% were less than 25 (least impacted) (Table 3). Most of the lakes that were moderately to heavily impacted by landscape human disturbances were distributed in the southern portion of the state (Fig. 2). Lakes that were least to marginally impacted were mainly distributed in the upper peninsula and northern lower peninsula, where the predominant land-cover types are water, wetland, forest, and grassland.

More inline lakes were impacted by landscape human activities than other lake types. Of the lakes that were heavily impacted by human activities, $92 \%$ were inline, $6 \%$ were disconnected, and $2 \%$ were headwater lakes. In contrast, of the lakes that were least impacted by human activities, $39 \%$ were inline, $46 \%$ were disconnected, and $15 \%$ were headwater lakes. More small lakes $(<40 \mathrm{ha})$ were impacted than medium to large lakes. For inline lakes, $90 \%$ of the 221 lakes that were heavily impacted were lakes less than 40 ha, 9\% were between 40 and 405 ha, and $<1 \%$ was greater than 405 ha. For disconnected and headwater lakes, all 17 of the lakes that were heavily impacted were lakes less than 40 ha.

When the top 2 human disturbances in each lake were considered, all 42 variables influenced disturbance index scores for at least 1 lake. The disturbance variable having the greatest influence on lake condition varied among lakes. Total nutrient yields and farm animal density affected the highest number of lakes (2659 and 2563 lakes, respectively), agricultural land use affected a moderate
Table 2 Mean, median, range, and standard deviation of lake indicator variables from a subset of lakes, which were used for assessing human disturbance

\begin{tabular}{lllll}
\hline Disturbance variables & Mean & Median & Range & $\begin{array}{l}\text { Standard } \\
\text { deviation }\end{array}$ \\
\hline Summer hypolimnon depth with DO $\leq 0.5 \mathrm{mg} / \mathrm{L}(\mathrm{m})$ & 1.8 & 0.0 & $0-21.3$ & 3.4 \\
Percent water column with summer DO $\leq 0.5 \mathrm{mg} / \mathrm{L}$ & 11.6 & 0.0 & $0-75.0$ & 18.2 \\
Summer hypolimnon depth with DO $\leq 4.0 \mathrm{mg} / \mathrm{L}(\mathrm{m})$ & 4.0 & 2.2 & $0-24.1$ & 4.7 \\
Percent water column with summer DO $\leq 4.0 \mathrm{mg} / \mathrm{L}$ & 26.7 & 23.5 & $0.0-78.6$ & 24.8 \\
Summer chlorophyll- $a(\mu \mathrm{g} / \mathrm{L})$ & 4.6 & 3.1 & $0.0-70.8$ & 6.8 \\
Summer Secchi disk reading $(\mathrm{m})$ & 3.3 & 3.2 & $0.71-8.5$ & 1.4 \\
Summer total nitrogen $(\mathrm{mg} / \mathrm{L})$ & 0.65 & 0.61 & $0.12-1.46$ & 0.28 \\
Summer total phosphorus $(\mathrm{mg} / \mathrm{L})$ & 0.02 & 0.02 & $0.00-0.19$ & 0.02 \\
Fish index of biotic integrity & 62 & 61 & $20-108$ & 16 \\
Shoreline dock density $(\mathrm{No} . / \mathrm{km})$ & 10 & 6 & $0-49$ & 11 \\
Shoreline armoring $(\%)$ & 21 & 11 & $0-94$ & 22 \\
Shoreline woody debris $($ diameter $\geq 7.6 \mathrm{~cm})(\mathrm{No} . / \mathrm{km})$ & 18 & 5 & $0-594$ & 6 \\
\hline
\end{tabular}


Table 3 Lake human disturbance scores by lake type and lake size

\begin{tabular}{|c|c|c|c|c|c|c|c|}
\hline \multirow[t]{2}{*}{ Lake type; size } & \multicolumn{4}{|c|}{ Disturbance scores and rating } & \multicolumn{3}{|c|}{ Disturbance scores percentile values } \\
\hline & $\begin{array}{l}<25(\%) \\
\text { Least }\end{array}$ & $\begin{array}{l}25-50(\%) \\
\text { Marginal }\end{array}$ & $\begin{array}{l}50-75(\%) \\
\text { Moderate }\end{array}$ & $\begin{array}{l}>75(\%) \\
\text { Heavy }\end{array}$ & 10 & 50 & 90 \\
\hline Disconnected; $<40$ ha & $2,566(44)$ & $1,339(49)$ & $177(40)$ & $15(6)$ & 7 & 18 & 43 \\
\hline Disconnected; 40-405 ha & $115(2)$ & $74(3)$ & $2(0)$ & $0(0)$ & 7 & 20 & 37 \\
\hline Disconnected; $>405$ ha & $0(0)$ & $1(0)$ & $0(0)$ & $0(0)$ & 27 & 27 & 27 \\
\hline Headwater; $<40$ ha & $788(13)$ & $411(15)$ & $61(14)$ & $5(2)$ & 19 & 19 & 44 \\
\hline Headwater; 40-405 ha & $93(2)$ & $41(2)$ & $1(0)$ & $0(0)$ & 7 & 17 & 38 \\
\hline Headwater; $>405$ ha & $2(0)$ & $1(0)$ & $0(0)$ & $0(0)$ & 23 & 23 & 42 \\
\hline Inline; $<40$ ha & $1750(30)$ & $706(26)$ & $178(40)$ & 199(83) & 2 & 17 & 62 \\
\hline Inline; 40-405 ha & $451(8)$ & $150(5)$ & $24(5)$ & $20(8)$ & 2 & 12 & 40 \\
\hline Inline; $>405$ ha & $74(1)$ & $10(0)$ & $4(1)$ & $2(1)$ & 1 & 7 & 35 \\
\hline All types and sizes & $5839(63)$ & 2733(29) & $447(5)$ & $241(3)$ & 3 & 18 & 45 \\
\hline
\end{tabular}

Note: The numbers in parentheses for the bottom row ("All types and sizes") are percentages calculated by the row total. The numbers in parentheses for the others are percentages calculated by the column total

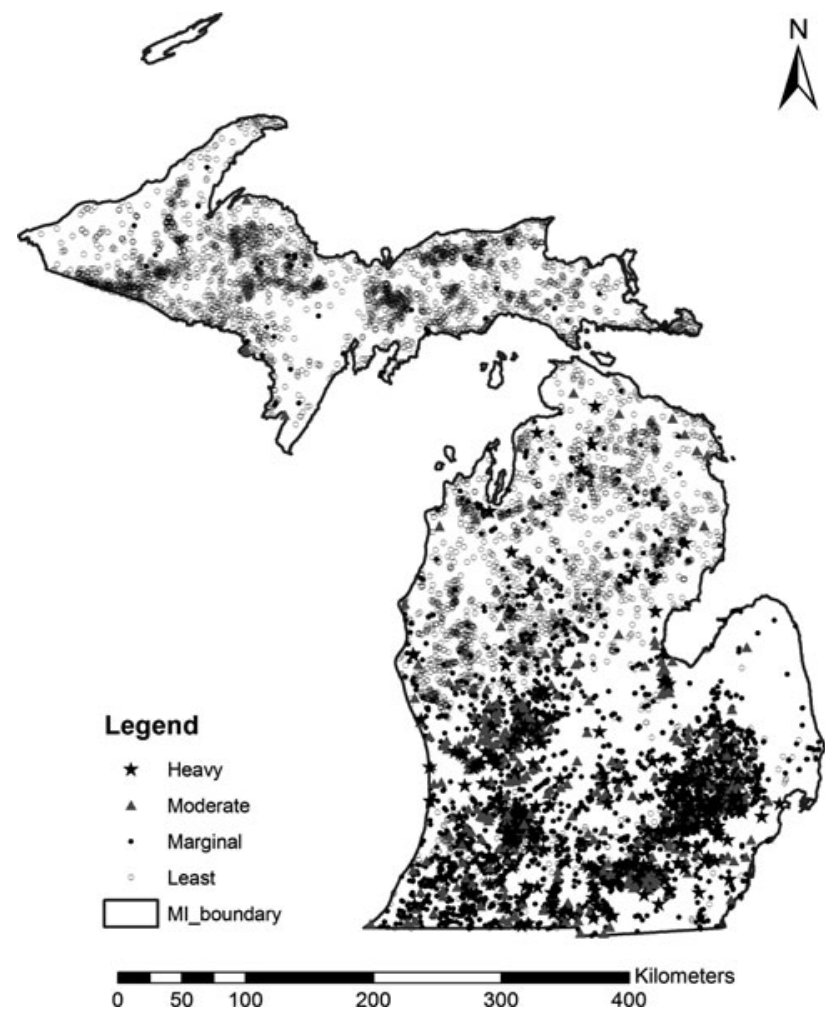

Fig. 2 Spatial distribution of Michigan lakes that were least, marginally, moderately, and heavily impacted by landscape human activities

number of lakes (1442 lakes), point-source pollution and road variables each affected fewer than 10 lakes, and the other disturbances affected $10-447$ lakes. The variable representing toxic release inventory sites that do not drain directly to surface waters was not among the top ranked disturbances for any lake. The disturbance variables having the second greatest
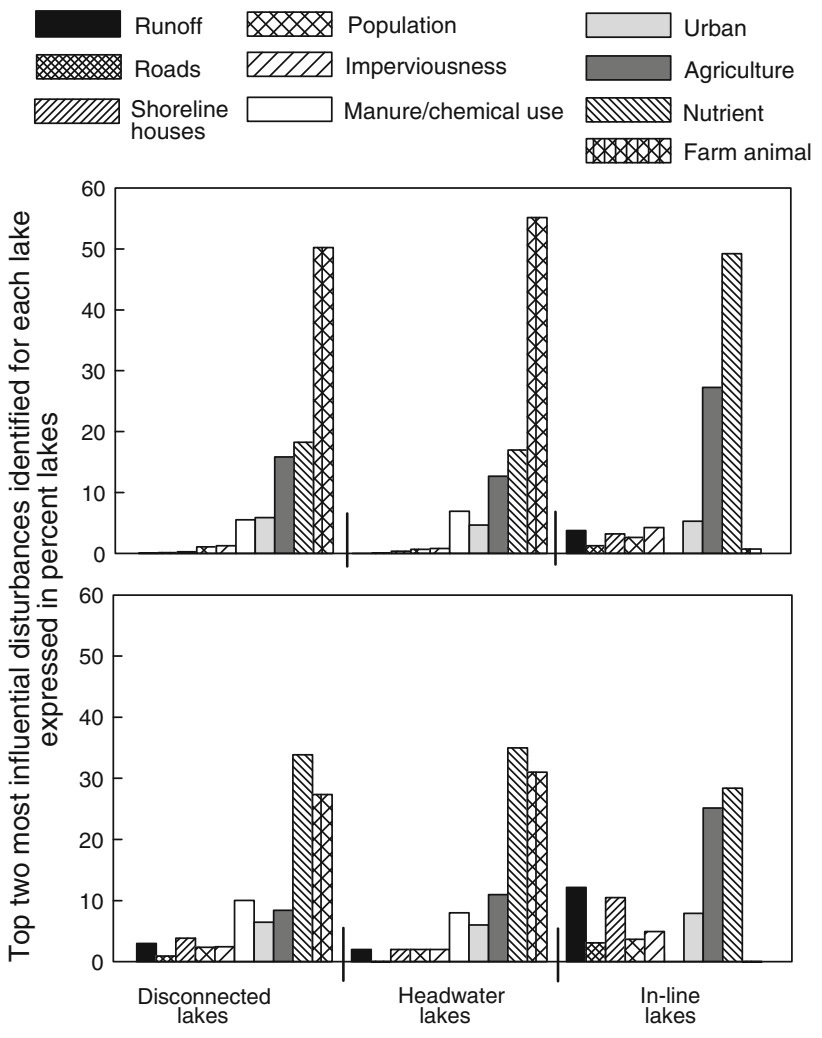

Fig. 3 Comparison of the differences in landscape human-disturbance factors that had the greatest (top panel) and second greatest (lower panel) influence on lake condition among disconnected, headwater, and inline lakes

influence on lake condition also varied among lakes. Total nutrient yields affected the highest number of lakes (2607 lakes); farm animal density, shoreline house density, catchment runoff, and urban land use affected a moderate number of lakes (548-1611 lakes); densities of mines and toxic release 
inventory sites, each, affected fewer than 10 lakes; and the other variables affected 13-426 lakes.

The top two disturbances differed among lake types (Fig. 3). The majority of disconnected and headwater lakes were influenced by farm animal density and nutrient yield, whereas the majority of inline lakes were influenced by nutrient yields and agricultural land uses. Among disturbances having the greatest influence on lake condition, farm animals affected much higher percentages of lakes (50 and 55\% respectively) for disconnected and headwater lakes than other disturbances $(<18 \%)$. In contrast, the difference in percentages of lakes affected by nutrient yields $(49 \%)$ and by other disturbances $(<27 \%)$ was much smaller for in-line lakes. Among disturbance variables having the second greatest influence on lake condition, nutrient yields and farm animal density affected a moderately higher percentage (25-37\%) of lakes than other disturbances $(<11 \%)$ for disconnected and headwater lakes; but nutrient yields and agricultural land uses affected a moderately higher percentage ( $28 \%$ and $25 \%$, respectively) of lakes than other disturbances $(<12 \%)$ for inline lakes.

The top two disturbance variables also differed among lakes with different human disturbance levels (Fig. 4). For disturbances having the greatest influence on lake condition, the variables that affected the highest number of lakes

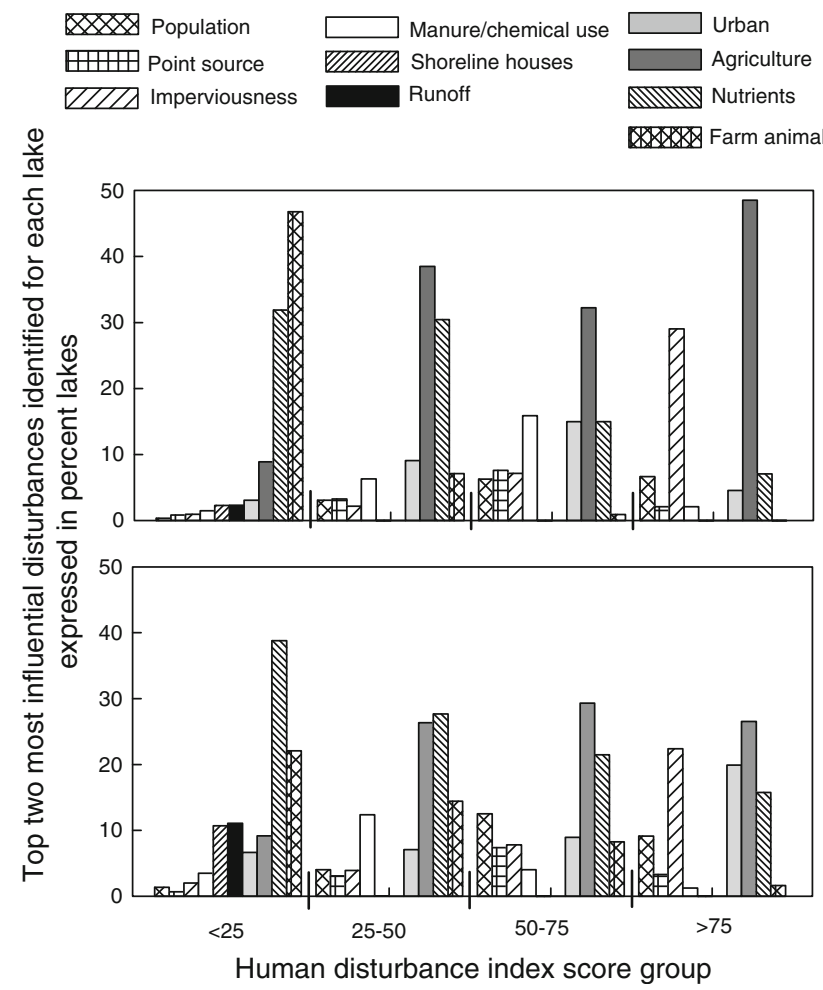

Fig. 4 Comparison of the differences in landscape human disturbance factors that had the greatest (top panel) and second greatest (lower panel) influence on lake condition among lake groups with different levels of human disturbances were farm animal density (47\% lakes) and nutrient yields (32\% lakes) for lakes with disturbance scores less than 25 , were agricultural land uses (38\% lakes) and nutrient yields (30\% lakes) for lakes with disturbance scores between 25 and 50, were agricultural land uses (32\% lakes) for lakes with disturbance scores between 50 and 75 , and were agricultural land uses (49\% lakes) and imperviousness (29\% lakes) for lakes with disturbance scores greater than 75. For disturbances having the second greatest influence on lake condition, the variables that affected the highest number of lakes were nutrient yields (39\% lakes) and farm animal density (22\% lakes) for lakes with disturbance index scores less than 25, were nutrient yields (28\% lakes) and agricultural land uses (26\% lakes) for lakes with disturbance scores between 25 and 50, were agricultural land uses (29\% lakes) and nutrient yields (21\% lakes) for lakes with disturbance scores between 50 and 75 , and were agricultural land uses (27\% lakes), imperviousness (22\% lakes), and urban land uses (and 20\% lakes) for lakes with disturbance scores greater than 75 .

\section{Discussion}

Our results indicated that the majority of inland lakes in Michigan are in good condition. A higher percentage of large lakes, disconnected lakes, and headwater lakes are in better condition than small lakes and inline lakes. This might be related to the fact that large lakes, disconnected lakes, and headwater lakes generally have smaller catchment area-to-lake area ratios. In these lakes, the amount of landscape alteration per unit lake area or volume is relatively small and, consequently, has relatively less impact. Most of the moderately to heavily impacted lakes are in southern Michigan, where agricultural, urban, and industrial activities are concentrated. The most common influential disturbance factors are farm animal densities and nutrient yields for headwater and disconnected lakes and agricultural land uses and nutrient yields for inline lakes. Such results are different from those for streams in that the most common influential disturbance factors are nutrient yields for cold/cool-water and urban land use for warmwater streams in Michigan (Wang and others 2008).

We developed a novel assessment approach that takes advantage of readily available landscape disturbance data and GIS technology. Our approach is unique because it can be used to assess impairment condition for all lakes in a region, identify key human disturbances impacting lakes, and identify the location of all lakes in a region that are likely impaired. Our approach differs from traditional lake assessments that exclusively use in-lake indicators or stressors. Our approach is based on the understanding that landscape alterations resulted from human disturbances 
(e.g., urbanization, agriculture, silverculture, mining, industry, recreation, population, and road) in local and upland influence in-lake conditions (e.g., nutrient, transparency, DO concentration, sediment, substrate, plankton, benthos, macrophyte, fish, quantity and quality of aquatic habitat, and overall ecosystem function and process). These alterations in landscape condition degrade in-lake physicochemical and biological conditions and, hence, overall lake condition. Traditional assessment using in-lake indicators or stressors focuses on symptoms and is valuable for addressing management and regulatory issues on targeted lakes or for reporting on the proportion of waters in a region that fail to meet their designated uses. Traditional approaches, however, fail to provide information on sources of impairment and on status of unsampled lakes. Such information is critical for developing management strategies and policies to protect the condition of the entire resource-in this case, the entire population of lakes in a region. Our assessment using landscape human disturbances focuses on the sources of degradation. Because a landscape-based assessment provides information on all lakes in a region, sources of impairment, and status of unsampled lakes, our approach provides a cost-effective means to conduct statewide or regional lake condition assessments and to develop large-scale management strategies that target individual lakes.

Our approach allows for the inclusion of all available human-disturbance measures in the lake assessment process. Some human-disturbance measures, such as shoreline house density and urban land use, were influential on a limited number of lakes. If these disturbances were excluded because they played a minor role in determining regional lake conditions, the primary determinant of lake condition for this small set of lakes would have been misidentified. The ability to include all human-disturbance measures in lake assessment has important management implications. Identifying key disturbances and where they are located enable managers and policy makers to more effectively determine the type of management strategies that should be developed and where they should be implemented.

Our approach eliminates the need of identifying reference conditions (least disturbed lakes), a critical step commonly used in bioassessment of aquatic systems. The purpose of establishing reference condition is to reduce the influence of natural factors on indicators so that comparison of conditions between reference and test lakes allows the determination of disturbance severity for test lakes. The recommended process for selecting reference lakes includes identifying relatively homogeneous lake regions, classifying lakes to reduce catchment, morphology, and network position influences on physicochemical and biological indicators, and evaluating levels of local and landscape disturbances for selecting least disturbed lakes. These tasks are usually done by expert consensus, biological lake survey, paleolimnology, evaluation of historical data, or prediction of expected conditions using ecological models (US EPA Lake and Reservoir Bioassessment and Biocriteria Technical Guidance Document, http://www. epa.gov/owow/monitoring/tech/lakes.html). Because our analysis included both natural and disturbance variables as predictors in our CCRA analysis, the weights calculated for each disturbance accounted for the influence of natural variation in climate, lake morphology, network position, and other natural landscape characteristics. Additionally, because our approach simultaneously accounted for the natural setting of all lakes in Michigan, there is no need for regionalization and classification to identify reference lakes.

Our approach generates a single-valued lake-disturbance index that provides an estimate of in-lake physicochemical and biological weighed summary of multiple disturbance factors. Our approach represents a substantial improvement over traditional lake assessment approaches that have largely relied on one type of in-lake stressor or indicator, such as the trophic state index (Carlson 1977) or various biotic indexes based on fish (e.g., Drake and Pereira 2002; Lyons and others 2000; Minns and others 1994; Schulz and others 1999), macroinvertebrates (e.g., Lewis and others 2001; Ma and others 2008), macrophytes (Melzer 1999; Nichols and others 2000), and diatoms (e.g., Dixit and Smol 1994; Stenger-Kovács and others 2007). Although those approaches have used landscape disturbance to justify their index values, they generally quantified only one or two dominant human-induced disturbances. Our single-valued lake-disturbance index takes into account not only traditionally used indicators (e.g., such as nutrients and biological factors) but also includes physical habitat measures that are important for vertebrate and invertebrate assemblages such as anoxia and hypoxia water volume, large woody debris, and shoreline habitat modification.

Although our approach using landscape disturbances to directly assess inland lake impairment condition has not been done previously, efforts in using landscape approach to directly assess aquatic system condition are not new. In a comparison of assessment approaches, Wang and others (2006a) recommended that linking landscape human disturbances with indicators and stressors in aquatic systems is of utmost important for pinpointing problem sources to provide a focus for effective lake management. In assessing the US portion of Great Lakes catchment conditions, Danz and others (2007) categorized landscape human disturbances into five groups, then conducted a principle component analysis for each group, and simply summarized the first principle of each group for all the five groups to calculate a catchment disturbance index. Mattson and 
Angermeier (2007) assessed 107 subwatersheds condition in the upper Tennessee River by summarizing landscape human disturbances into 12 threats and then subjectively rated their importance in influencing river ecosystem integrity. Multiplying the rating score by the levels of the 12 disturbance variables, they calculated a summary disturbance index for each subwatershed. Halpern and others (2008) reported a method that estimated the impacts of 17 anthropogenic variables on the world's oceans. They assessed the ecosystem condition for the entire world ocean using a disturbance index that integrated 17 disturbance variables based on weights generated by expert opinion. Wang and others (2008) assessed all stream segments between confluences for the entire state of Michigan using landscape anthropogenic disturbances from stream buffers and catchments. They used multivariate statistical procedures to calculate the weights for disturbance variables based on their influences on fish indicators and then applied the weights to disturbance variables for streams where fish data were not available. Although these studies used different methods to integrate disturbance variables into a single system disturbance index, they demonstrate the feasibility of using landscape anthropogenic measures for large-spatial-scale aquatic system condition assessment.

There are several challenges in our approach that need to be addressed in future studies. For instance, our suite of humandisturbance variables is incomplete and the spatial resolution of some variables is too coarse. For example, the number of riparian sanitary systems, chemical treatments for macrophytes and algal blooms, and modification of shoreline substrate and vegetation are known to impact lake condition (e.g., Jennings and others 1999; Pothoven and others 1999; Scopel and others 2006). Data for these disturbances, however, were not available and were not included in our assessment. Furthermore, the resolution of nutrient yield data is at 8-digit hydrologic units and the resolution of fertilizer, herbicide, pesticide, and manure data is at the county level. These spatial scales are fairly coarse for assessing lakes, especially lakes having relatively small catchment areas. Improvements in data availability and resolution will substantially improve future efforts to assess lake condition using a landscape-based approach.

It is important to recognize that our lake condition assessment is only the first of a multiple-step process for development of tools for lake management. This first step is a process for determining a surrogate measure of indicators and stressors based on landscape human disturbance types and levels. This allows ranking lake conditions by lake type, size, and impairment status for all lakes in Michigan. It also allows identifying sources of major disturbances for each lake. In addition to the landscape-disturbance influences, there are many other factors, such as natural variation, localized perturbations, type and intensity of human uses, and social and economic importance of the lakes, which also critically influence management priorities. Our first-tier analysis provides a tool for identifying the spatial scale at which management activities should be focused. For example, in-lake, shoreline, or local management efforts are likely to be effective only for waters that have minimal landscape disturbance or where landscape disturbances are under control (Wang and others $2003,2006 b$ ). Our first-tier analysis also provides a way to identify lakes with minimal landscape disturbance, which is essential for establishing expected natural lake condition.

Additional steps are needed in order to improve the ability of lake managers and policy makers to effectively use limited resources for addressing environmental issues. First, a secondtier lake ranking system based on human uses, social values, economic importance, and effectiveness of potential management actions would provide a quantitative way for prioritizing lakes for protection, enhancement, and restoration. Second, identification of a mechanism linking landscape disturbance to specific lake condition indicators is necessary for development of Total Maximum Daily Loads and for improvement of specific lake conditions to meet Clean Water Act mandates (Novotny and others 2005). Although such an effort was beyond the scope of our study, this issue should be addressed in future work. Finally, our assessment approach can be improved by increased resolution and accuracy of landscape-disturbance databases and by inclusion of additional information, such as occurrences of invasive species and additional disturbances that might have potentially impacted lake condition. Although our study presents a relatively coarse-level assessment, it does provide a framework and process that can incorporate additional steps and information when these sources become available, which will improve the overall ability of lake managers and policy makers to effectively improve lake conditions.

Acknowledgments We thank Paul Seelbach for providing vision and encouragement in the development of the statewide lake database; Patricia Soranno, Mary Bremigan, Kendra Cheruvelil, and Sherry Martin for in-depth discussion in the early phase of the lake database development; Arthur Cooper for assistance with GIS processes; and Minako Edgar for preparation of Michigan maps. We are grateful to Mark Bain and two anonymous reviewers for comments and suggestions that improved the manuscript. This project was financially supported by Federal Aid in Sport Fishery Restoration Program, Project F-80-R through the Fisheries Division of the Michigan Department of Natural Resources and Environment and a federal grant for State Wildlife Action Plan through the University of Michigan.

\section{References}

Borcard D, Legendre P, Drapeau P (1992) Partialling out the spatial component of ecological variation. Ecology 73:1045-1055

Breck JE (2004) Compilation of databases on Michigan lakes. Fisheries Technical Report 2004-2, Michigan Department of Natural Resources, Ann Arbor 
Carlson RE (1977) A trophic state index for lakes. Limnology and Oceanography 22:361-369

Danz NP, Niemi GJ, Regal RR, Hollenhorst TP, Johnson LB, Hanowski JM, Axler RP, Ciborowski JH, Hrabik T, Brady VJ, Kelly JR, Morrice JA, Brazner JC, Howe RW, Johnston CA, Host GE (2007) Integrated measures of anthropogenic stress in the U.S. Great Lakes basin. Environmental Management 39:631-647

Dixit SS, Smol JP (1994) Diatoms as indicators in the environmental monitoring and assessment program-surface water (EMAP-SW). Environmental Monitoring and Assessment 31:275-306

Drake MT, Pereira DL (2002) Development of a fish-based index of biotic integrity for small inland lakes in central Minnesota. North American Journal of Fisheries Management 22:1105-1123

Drake MT, Valley RD (2005) Validation and application of a fishbased index of biotic integrity for small central Minnesota lakes. North American Journal of Fisheries Management 25:1095-1111

Fausch KD, Lyons J, Karr JR, Angermeier PL (1990) Fish communities as indicators of environmental degradation. American Fisheries Society Symposium 8:123-144

Halpern BS, Walbridge S, Selkoe KA, Kappel CV, Micheli F, D'Agrosa C, Bruno JF, Casey KS, Ebert C, Fox HE, Fujita R, Heinemann D, Lenihan HS, Madin EMP, Perry MT, Selig ER, Spalding M, Steneck R, Watson R (2008) A global map of human impact on marine ecosystems. Science 319:948-952

Jennings MJ, Bozek MA, Hatzenbeler GR, Emmons E, Staggs MD (1999) Cumulative effects of incremental shoreline habitat modification on fish assemblages in north temperate lakes. North American Journal of Fisheries Management 19:18-27

Karr JR, Chu EW (1999) Restoring life in running waters, better biological monitoring. Island Press, Covelo, CA

Laessig RE, Duckett EJ (1979) Canonical correlation analysis: potential for environmental health planning. American Journal of Public Health 69:353-359

Lewis PA, Klemm DJ, Thoney WT (2001) Perspectives on use of a multimetric lake bioassessment integrity index using benthic macroinvertebrates. Northeastern Naturalist 8:233-246

Lyons J, Gutiérrez-Hernández A, Días-Pardo E, Soto-Galera E, Medina-Nava M, Pineda-López R (2000) Development of a preliminary index of biotic integrity (IBI) based on fish assemblages to assess ecosystem condition in the lakes of central Mexico. Hydrobiologia 418:57-72

Ma T, Huang Q, Wang H, Wang Z, Wang C, Huang S (2008) Selection of benthic macroinvertebrate-based multimetrics and preliminary establishment of biocriteria for the bioassessment of the water quality of Taihu Lake, China. Acta Ecologica Sinica 28:1192-1200

Martin SL, Soranno PA (2006) Lake landscape position: relationships to hydrologic connectivity and landscape features. Limnology and Oceanography 51:801-814

Mattson KM, Angermeier PL (2007) Integrating human impacts and ecological integrity into a risk-based protocol for conservation planning. Environmental Management 39:125-138

Melzer A (1999) Aquatic macrophytes as tools for lake management. Hydrobiologia 395-396:181-190

Minns CK, Cairns VW, Randall RG, Moore JE (1994) An index of biotic integrity (IBI) for fish assemblages in the littoral zone of Great Lakes' area of concern. Canadian Journal of Fisheries and Aquatic Sciences 51:1804-1822

Nichols S, Weber S, Shaw B (2000) A proposed aquatic plant community biotic index for Wisconsin lakes. Environmental Management 26:491-502

Norris RH, Hawkins CP (2000) Monitoring river health. Hydrobiologia 435:5-17
Novotny V, Bartošová A, O’ Reilly N, Ehlinger T (2005) Unlock the relationship of biotic integrity of impaired waters to anthropogenic stresses. Water Research 39:184-198

Pothoven SA, Vondracek B, Pereira DL (1999) Effects of vegetation removal on bluegill and largemouth bass in two Minnesota lakes. North American Journal of Fisheries Management 19:748-757

RI ES (2002) PC ARC/GIS Version 8.2. Environmental System Research Institute, Redlands, CA

SAS (2004) SAS/STAT user's guide. Version 9.1.2. SAS Institute, Cary, NC

Schulz EJ, Hoyer MV, Canfield DE Jr (1999) An index of biotic integrity: a test with limnological and fish data from sixty Florida lakes. Transactions of the American Fisheries Society 128:564-577

Scopel CO, Harris J, McLellan SL (2006) Influence of nearshore water dynamics and pollution sources on beach monitoring outcomes at two adjacent Lake Michigan beaches. Journal of Great Lakes Research 32:543-552

Shuter BJ, Schlesinger DA, Zimmerman AP (1983) Empirical predictors of annual surface water temperature cycles in North American lakes. Canadian Journal of Fisheries and Aquatic Science 40:1838-1845

Smith RA, Schwarz GE, Alexander RB (1997) Regional interpretation of water-quality monitoring data. Water Resources Research 33:2781-2798

Stenger-Kovács K, Buczkó K, Hajnal É, Padisák J (2007) Epiphytic, littoral diatoms as bioindicators of shallow lake trophic status: trophic diatom index for lakes (TDIL) developed in Hungary. Hydrobiologia 589:141-154

Suter GW II, Norton SB, Cormier SM (2002) A methodology for inferring the causes of observed impairments in aquatic ecosystems. Environmental Toxicology and Chemistry 21:1101-1111

ter Braak CJF, Smilauer P (1998) CANOCO reference manual and user's guide to Canoco for Windows: Software for Canonical Community Ordination (version 4). Microcomputer Power, Ithaca, NY

USEPA (US Environmental Protection Agency) (2000) Stressor identification guidance document. EPA-822-B-00-025. US EPA, Washington, DC

USEPA (US Environmental Protection Agency) (2003) Elements of a state water monitoring and assessment program. EPA 841-B-03003. Assessment and Watershed Protection Division, Office of Wetlands, Oceans and Watershed. US EPA, Washington, DC

Wang L, Lyons J, Rasmussen P, Kanehl P, Seelbach PW, Simon T, Wiley M, Baker E, Niemela S, Stewart M (2003) Influences of landscape- and reach-scale habitat on stream fish communities in the Northern Lakes and Forest ecoregion. Canadian Journal of Fisheries and Aquatic Science 60:491-505

Wang L, Seelbach PW, Hughes RM (2006a) Introduction to landscape influences on stream habitats and biological assemblages. American Fisheries Society Symposium 48:1-23

Wang L, Seebach PW, Lyons J (2006b) Effects of levels of human disturbance on the influence of watershed, riparian, and reach scale factors on fish assemblages. American Fisheries Society Symposium 48:199-219

Wang L, Brenden T, Seelbach PW, Cooper A, Allan D, Clark R Jr, Wiley M (2008) Landscape based identification of human disturbance gradients and references for streams in Michigan. Environmental Monitoring and Assessment 141:1-17

Wehrly, KE, Carter GS, Breck JE (2010) Standardized sampling methods for the inland lakes status and trends program. Fisheries Special Report. Michigan Department of Natural Resources and Environment, Ann Arbor 